\title{
Questões pedagógicas na reformulação do currículo do ensino médio ${ }^{1}$
}

\author{
Leila de Almeida de Locco $^{2}$
}

\begin{abstract}
RESUMO
O texto tem como finalidade apresentar uma reflexão sobre a história do Ensino Médio nas últimas três décadas no Estado do Paraná, considerando-se a estrutura, $\mathrm{o}$ aspecto legal, a metodologia de reformulação curricular e a articulação com o ensino de $3^{\circ}$ grau.
\end{abstract}

Palavras-chave: ensino médio, reformulação curricular, administração

Ao revisitar a história do Ensino Médio no Estado do Paraná, a partir da década de 60 , considera-se a estrutura, $\mathrm{o}$ aspecto legal, a metodologia de reformulação curricular e a articulação com o $3^{\circ}$ grau.

Na década de 60 implantava-se a primeira Lei de Diretrizes e Bases, em que o ensino médio, dividido em dois ciclos, o Ginasial e o Colegial, incorporava a estrutura vigente nas Leis Orgânicas, porém num mesmo grau e num mesmo ciclo. Assim é que o segundo ciclo, o colegial, assim se apresenta: o Secundário (Educação Geral) e os ramos profissionalizantes Comercial, Normal, Agrícola e Industrial. No Paraná aparece, ainda, o ensino politécnico e a possibilidade do Secundário (Educação Geral), na terceira série, ser organizado com currículo diversificado, visando ao preparo dos alunos para os cursos superiores. Daí que, na prática tivemos a bifur-

\footnotetext{
'Texto preliminar apresentado por ocasião do "Seminário Educacional no Paraná de Reformulação Curricular Ensino Médio", promovido pela SEED e NRE, Núcleos de Cascavel, Área Metropolitana, São José dos Pinhais e Lapa, realizado em 1997.

Professora Assistente - DTPEN - ED - UFPR

Olhar de professor, Ponta Grossa, 2 (2):43-51, nov. 1999.
} 
cação do curso dito Científico (destinado às áreas exatas e biológicas) e o Clássico (humanas). Nesse momento o vestibular era por grandes áreas e, portanto, estava articulado a essa reformulação. Embora os egressos do curso técnico tivessem acesso ao vestibular, em princípio já estavam prejudicados, pois tinham uma carga horária menor nas disciplinas de educação geral, objeto do vestibular. Por outro lado, não se tem notícia da valorização (pontuação dos cursos técnicos) prevista em lei, para os cursos de ensino superior da mesma área.

Ao final da década de 60 , observa-se o seguinte cenário: cursos secundários com o Científico e Clássico nas cidades grandes, apenas o $\mathrm{Ci}$ entífico nas cidades menores e nas mais novas; o curso de magistério colegial, turno diurno, substituindo os normais regionais; os colégios agrícolas (período integral) consolidando-se a partir dos ginásios agrícolas; os cursos de contabilidade (período noturno); e os cursos na área industrial, na Escola Técnica Federal (diurno e noturno) e no Instituto Politécnico (IPE). Essa estrutura, preconizada no sistema estadual de ensino através da lei número 4978/64, operacionaliza-se nos documentos do governo do Estado do Paraná para cada um dos graus ou ramos profissionalizantes, mas não se tem notícias do processo para se chegar a essa estrutura curricular.

Se a década de 60 se caracterizouse pela Organização do Sistema Es- tadual de Ensino cumprindo o princípio de descentralização preconizado pela Lei número 4024/61, a década de 70 prioriza a Organização da Escola. Com a implantação da Lei 5692/ 71, o Estado como Sistema planeja as tarefas de reformulação, apresentando um cronograma gradativo de implantação em que os municípios estavam categorizados em pólo, Expansão I, II, III e IV, sendo que o ensino de primeiro grau iniciou um ano antes do segundo grau. Para essa implantação o Paraná reforça as unidades descentralizadas e onde existiam as Delegacias e Inspetorias Auxiliares, passou-se a ter as Inspetorias Regionais e Locais. Paralelamente, à essa estrutura existente cria-se uma estrutura para dar suporte aos trabalhos de reformulação da nova lei ou seja Núcleos Regionais de Orientação e Avaliação - NROAs e os Núcleos Locais de Orientação e Avaliação NLOAS. Os trabalhos de implantação eram de responsabilidade desses órgãos e por eles coordenados. A metodologia da reformulação era constituída de Seminários Regionais, nos quais participavam equipes pedagógicas, diretores e professores representantes. A seguir, trabalhos locais eram realizados, a saber: a socialização de seminários com as escolas que já ofereciam cursos profissionalizantes e/ou secundários e reuniões com os profissionais da comunidade para embasar as decisões sobre os cursos profissionalizantes a serem oferecidos. As temáticas trabalhadas 
nos seminários versavam sobre a nova legislação (lei/pareceres), profissionalização e mercado de trabalho, tarefas típicas das profissões, etc.

A Reforma era ampla e para implantar o ensino profissionalizante a escola tornou-se profissionalizante, o que exigiu, também, uma Reorganização Administrativa. O modelo adotado foi o dos Complexos Escolares, os quais agruparam escolas que, até então, ministravam o ensino primário, com outras que ofereciam o primeiro ciclo do secundário (Ginasial); com outras que ministravam primeiro e segundo ciclos do secundário; e, ainda, com outras que ministravam o curso profissionalizante.

Registraram-se muitas dificuldades na incorporação de escolas com tradição ou com identidade mais marcada, como foi o caso das que ofereciam o Curso Normal ou, ainda, na criação de novos cursos, para os quais não se tinha tradição, recursos humanos qualificados, nem recursos físicos e materiais apropriados.

Essas tarefas preparatórias deveriam culminar com o Plano de Implantação da Reforma do município e do complexo escolar, assim como com a elaboração do novo Regimento Escolar, em substituição ao Regimento Interno.

Concomitantemente, era preciso desencadear o processo de atualização de todos os docentes, equipes técnicas e administradores. Para tanto, a política de aperfeiçoamento de pessoal, à época, investiu nas Reci- clagens, coordenadas pelo CETEPAR - Centro de Treinamento do Magistério Paranaense, onde estavam centralizadas as atividades. Recomendava-se o repasse dos conteúdos trabalhados nessas Reciclagens, na volta dos participantes.

Com relação à qualificação de recursos humanos para as outras áreas profissionalizantes, teve-se os Cursos de Esquema I, ofertados em diferentes regiões. Esses recursos humanos deveriam servir à estrutura dos Colégios Polivalentes que se implantaram na década.

Nesse período, implanta-se o Vestibular Unificado, em articulação com a proposta de Núcleo Comum. Parecia que se democratizava o ensino, que antes era dual e agora profissionalizante para todos. A rede pública faz esforços para assumir a profissionalização, organiza os estágios e implanta o serviço de Orientação Educacional em nível de primeiro grau para realizar as tarefas de Aconselhamento Vocacional, visando às escolhas em nível de segundo grau.

Paralelamente, e consoante com a política nacional, implanta-se o sistema de supervisão nos níveis central, regional, local e de escola, absorvendo os N.R.OA e N.L.OA, e caracterizando-se como um sistema paralelo que assegurava agilidade ao processo de consolidação da reforma de ensino.

No entanto, as escolas particulares não demonstraram o mesmo compromisso e, rapidamente, valeram-se 
das disciplinas instrumentais para fortalecer a Educação Geral, passando a oferecer uma profissionalização só de fachada. Enquanto isso, os cursinhos Pré-Vestibulares consolidamse nessas duas últimas décadas, configurando-se em sistemas paralelos e verdadeiros impérios em constante guerra uns contra os outros, manifestada pelas estatísticas à época dos Vestibulares.

Não demora muito e o modelo da profissionalização começa a enfraquecer com a implantação do Parecer no 76/75, das Habilitações Básicas, e respectiva Resolução que isentava do Estágio e diminuía as horas de profissionalização. Se antes a orientação era do Parecer 45/72 e respectiva Resolução, em que a profissionalização se dava em nível técnico e auxiliar, com o estágio em caráter obrigatório para as áreas primária e secundária, e obrigatoriedade para o Magistério e Saúde, na área terciária de Serviço, agora não mais se fazia necessária tal exigência. Uma grande parte das escolas adotou essa nova forma de profissionalização em nome de não ter mais o excedente no mercado de trabalho, uma vez que o treinamento far-se-ía em serviço.

O golpe na profissionalização é dado pela Lei 7044/82, quando há um retorno ao Curso só de Educação Geral, que no Paraná chamou-se Propedêutico, numa clara alusão à preparação para o $3^{\circ}$ grau, ficando dessa forma o $2^{\circ}$ grau um grau de passagem, sem identidade própria. Re- presentantes das Escolas foram chamados e voltavam com as instruções para que se implantassem os Cursos Propedêuticos e abrissem mão dos Cursos Profissionalizantes, ou então os justificassem. Foram feitas reuniões no interior das escolas para subsidiar tal decisão.

Os cursos profissionalizantes, para serem mantidos, precisavam de Justificativa. Assim é que os mesmos, tantos os regidos pelo Parecer 45/72 como os do Parecer 76/75, foram substituídos pelo Curso Propedêutico, que passou praticamente a ser obrigatório ou, quando muito, os dois tipos de cursos passaram a conviver na mesma escola.

É interessante ressaltar que o sistema do Paraná volta quase que à configuração anterior à Lei no 5692/71, em que havia os quatro ramos profissionais e o Curso de Educação Geral, sendo Magistério e Contabilidade em maior número, Agrícolas (10) e Industrial (1 Federal e 1 Estadual).

A criação dos Cursos Propedêuticos exigiu que o Conselho Estadual e a Secretaria de Educação se pronunciassem sobre a Preparação para o Trabalho, e a orientação foi pelo estabelecimento de Linhas de Preparação para o Trabalho numas dessas linhas, a de Preparação Universal, tinha-se que relacionar as disciplinas de Educação Geral com o Trabalho. Isso trouxe dificuldades para os professores que, por formação, não haviam sido preparados para tal. Era mais fácil incluir as discipli- 
nas aplicadas, tais como Redação Comercial e Matemática Comercial e Financeira, do que fazer a articulação com os conteúdos do Núcleo Comum.

Com o Governo Richa propôs-se a desaceleração da implantação de Escolas e/ou Cursos de $2^{\circ}$ grau, como pausa para a Avaliação e novas reformulações. Mais tarde o Curso de Magistério foi reformulado, numa metodologia bastante participativa, envolvendo desde a escola, o município, a região até o nível central. Utilizava-se o sistema de representação, que contemplava as diferentes disciplinas do Currículo do Curso, sendo que a sistematização ocorria em todas as esferas, a partir das propostas da(s) escola(s).

O nível central fez diagnósticos, traçou as diretrizes mais amplas e encarregou-se da sistematização e aprovação final do Documento. Essa proposta de Reformulação do Curso de Magistério foi construída a partir da estrutura dos Pólos de Magistério, constituída da escola de Magistério/ Núcleos Regionais de Educação, e Faculdades e/ou Universidades. Submetida à aprovação do C.E.E., a proposta foi considerada eclética e por conta das divergências na duração ( 3 ou 4 anos), teve-se problemas para sua aprovação.

Nesse mesmo momento, o Curso Noturno foi objeto de Reformulação, quando foi utilizada a estratégia de Comissão e Consultoria. Na Comissão estavam representantes da Escolas Noturnas dos diferentes
Núcleos Regionais de Ensino. Um dos avanços foi o fato da Comissão registrar no Documento Final, as Condições para a implantação da Proposta. Foram feitos seminários regionais e centrais.

Os outros Cursos - os Agrícolas e os de Contabilidade - foram gradativamente sendo reformulados utilizando-se do sistema de representantes e estratégias tais como reuniões/encontros e seminários, com a produção de documento contendo a Proposta.

Na gestão Álvaro Dias, nova reformulação do Curso Magistério e do Curso Regular de Educação Geral foi encetada e aí outra metodologia foi proposta. Como havia crítica às reformulações curriculares da década de 70, quando se elaboram as Revistas Currículo pelas equipes centrais de Currículo e, ao mesmo tempo, a dificuldade em avançar com as propostas vindas da base sem a definição de forma explícita de uma postura, partiu-se para uma sistemática a partir de Consultorias por área do saber. Elas seriam responsáveis pelo diagnóstico da sua área e por uma versão preliminar a ser discutida nos diferentes níveis, com o envio de sugestões a serem incorporadas ou não. Essas reformulações ocorreram concomitantemente e em conjunto com o primeiro grau, o que permitiu, pela primeira vez, uma reformulação articulada horizontal e verticalmente, congregando diferentes graus, modalidades, cursos de Educação Geral e 
Profissionalizante.

Dessa feita, a Linha foi explicitada e os Documentos - Proposta foram amplamente divulgados; os professores tiveram acesso a esses documentos que, no conjunto por curso, foram aprovados pelo CEE, devendo ser operacionalizados em nível de escola.

Após este revisitar das três últimas décadas, ficamos com a certeza de que, quando o Sistema tem vontade política, cria estratégias para avaliar (mesmo que precariamente) e para implantar novas propostas, sejam elas copiadas, impingidas, criadas ou recriadas. Mas esse Sistema tem falhado, no que se refere às tarefas de acompanhamento. Mesmo quando as propostas têm sido implantadas gradativamente, não se tem percebido preocupações reais com o acompanhamento regular, fato esse que se agrava quando a implantação é simultânea, exigindo acompanhamento mais intenso e/ou diferenciado. O processo de avaliação só é feito novamente quando os dispositivos legais assim o exigem ou, ainda, quando na troca de dirigentes, a mudança curricular é colocada como meta de sua gestão. Em decorrência disso, pouco se sabe da real efetivação dos currículos no interior das escolas e das salas de aula. Considere-se ainda, a falta de articulação das políticas de aperfeiçoamento de pessoal com as mudanças curriculares; ora demoram, ora não têm a intensidade que deveriam ter, ora não atendem a todos, ora não garantem a manutenção face à mobilidade dos docentes, etc.

Outra questão é a postura dos professores que não participam no exato momento da reformulação, com a justificativa de que a proposta veio de cima para baixo, e não se envolvem. Daí a necessidade das equipes reeditarem em todos os níveis a socialização das propostas para os que não participaram diretamente, para os novos, inclusive com a explicitação da metodologia utilizada no processo de reformulação.

Tem ocorrido, ainda, que processos de reformulação e/ou implantação já foram prejudicados quando coincidiram com movimentos grevistas e/ ou se deram em final de governo. Há que se considerar a fase de transição de um governo para outro e/ou as trocas de chefias de Departamento, quando os processos normalmente se interrompem. Outra questão importante a ser discutida é o fato das propostas serem "carimbadas", ou seja, é a proposta do governo tal, resultando em descompromisso, independentemente do seu valor pedagógico. Não deve ser descurada também a questão dos recursos financeiros, que podem atropelar, atrasar e/ou inviabilizar as reformas curriculares.

$\mathrm{Na}$ década de 80 , e com mais intensidade a partir da Constituição Federal de 88 e da Constituição Estadual do Paraná de 89 , a duras penas montou-se uma estratégia para discutir as proposições, levantar e incorporar sugestões, propor políticas, ava- 
liar políticas com a finalidade de interferir nas decisões. Para isso, contou-se com a estrutura das descentralizadas tanto do Sistema Estadual como das Associação dos Professores do Paraná, assim como com a atuação do Fórum Estadual em Defesa da Escola Pública. Daí a estranheza ao se receber políticas definidas "a priori" e poder apenas discutir o como incorporá-las. Isso é desestimulador, provoca a acomodação, além de não mobilizar para tarefas tão complexas e desafiadoras como as mudanças na estrutura e nos currículos dos cursos.

De nada valem pesados investimentos no momento da implantação, se não existir uma política de manutenção de qualidade dos Cursos, respaldada numa perspectiva diagnóstica de avaliação que possibilite o aperfeiçoamento constante do processo.

$O$ fato de não se possuir uma metodologia de acompanhamento curricular em termos de sistema, em que os níveis regional, local e escolar teriam tarefas específicas, vem acarretando a falta de registro de dados que vão se perdendo e/ou ficando apenas na memória dos que passam pelo sistema. Isso se agrava com o processo de mobilidade entre professores e equipes de ensino, resultando em descontinuidade dos processos de acompanhamento, mesmo que de forma assistemática. Daí a importância das equipes pedagógicas que sofrem o menor grau de mobilidade que os professores e que, permanecendo em suas funções, enquanto mudam as di- reções, chefias de Núcleo, chefes de Departamento, Secretários de Educação etc. , seriam as responsáveis pela continuidade dos processos de implantação, acompanhamento e avaliação das propostas curriculares. Porém, nem sempre o sistema tem garantido equipes que atuem diretamente com o segundo grau, o qual tem suas especificidades.

O cenário paranaense encontra-se às voltas com mais uma Reformulação Curricular. É para atender as exigências legais? Em princípio parece que sim, mas não é!!! O Paraná, desta vez, antecipou-se ou precipitou-se, apostando na aprovação do nível pós-médio, proposta bancada pelo Senador Darcy Ribeiro que não vingou no texto final da nova lei, e lançou o PROEM para imediata implantação. Não houve discussão anterior a essa decisão, somente após resposta às pressões de pais, alunos, CEE e sociedade organizada. Só então a discussão ganhou espaço na Comissão de Educação da Câmara dos Deputados, cabendo aos Conselhos Escolares e, em última instância, decidir sobre a supressão dos Cursos Profissionalizantes. Seria uma jogada de marketing? Se o pós-médio tivesse sido aprovado, o Paraná estaria sendo o carro-chefe da proposta do MEC, o modelo, mas isso não ocorreu. E agora, que fazer?

O PROEM barateia o custo de ensino de segundo grau e por isso tem o aval dos agentes financeiros. Ao mesmo tempo, interessa desprofissio- 
nalizar o ensino de $2^{\circ}$ grau, pois não se teria mais que atender a toda clientela e sim apenas os egressos, que são em menor número, graças aos índices de seletividade no interior desse grau de ensino. Ao mesmo tempo, poderia alargar a faixa de atendimento, considerando as pressões conjunturais que exigem esse nível de escolaridade e o fato de estar se desvencilhando do ensino de primeiro grau, em processo acelerado de municipalização na faixa de primeira a quarta série. Ressente-se também de uma política específica para o Curso de Magistério, que igualmente fez parte da proposta do PROEM, sem ter uma proposta concreta para o "dito" pós-médio e sem uma discussão com as instituições de terceiro grau que deveriam, como horizonte, assumir essa formação e que, na nova LDB, tiveram estabelecido um período para o cumprimento dessa exigência. Considere-se ainda a extinção do Vestibular Unificado e as possibilidades dos novos processos de seleção.

E o que dizer ou fazer diante da nova proposta anunciada pelo MEC, a ser concluída em outubro, onde o $2^{\circ}$ grau teria $75 \%$ de disciplinas comuns (Educação Geral) e 25\% de matérias específicas para aprofundar e/ou para se iniciar na parte profissionalizante? Como compatibilizar esse cenário com as novas formas de acesso ao $3^{\circ}$ grau, tendo os resultados do Exame Nacional de Ensino Médio (ENEM) como uns dos prováveis itens a serem considerados?

Os alunos que escolherem no $2^{\circ}$ grau os $25 \%$ na área profissionalizante, ficarão certamente prejudicados nas novas formas de seleção. Seria mais uma forma de desencorajar a profissionalização, em nível de segundo grau, correndo paralelamente? Vide a Reformulação das Escolas Técnicas, em que a proposição é desvincular a Educação Geral da Formação Especial... E quanto aos alunos que tiverem insucesso nos novos processos seletivos? O sistema os atenderá num retorno, teremos os Centros Profissionalizantes que não vingaram na Lei $5962 / 71$ ? E a terminalidade para os alunos que não desejam de imediato ou não podem prosseguir os estudos ou, ainda, os que precisam da formação profissionalizante para ingressar no mercado de trabalho ou para manter o emprego?

Esta será mais uma Reformulação Curricular que terá apenas fase de aceitação da proposta, operacionalização e implantação, sem prever uma discussão mais ampla com a comunidade interessada - pais, alunos, sociedade civil organizada, sem prever mecanismos de acompanhamento e avaliação.

\section{REFERÊNCIAS BIBLIOGRÁFICAS}

1 BRASIL. Constituição da república federativa do Brasil, 1988.

2 LOCCO, Leila de A. de. A supervisão educacional no Paraná: uma análise crítica. São Paulo: 1987. Dissertação PUC/SP. 
3 PARANÁ. Secretaria de Estado da Educação. Políticas da SEED: fundamentos e explicitação. Curitiba, 1983.

4 - Secretaria de Estado da Educação e Cultura. Centro de Pesquisas Educacionais. Currículo, ano 1, n.1, 1973.

5 - Secretaria de Estado dos Negócios da Educação e Cultura. Sistema de Supervisão, 1974.

6 - Conselho Estadual de Educação. Lei n. 4978 de 5/12/64. Sistema Estadual de Ensino.

7 —. Constituição do Estado do Paraná, 1989.

8 ROMANELLI, O de O. História da educação brasileira. 2.ed. Petró-polis : Vozes, 1980. 